\title{
Backside Wear Is Not Dependent on the Acetabular Socket Design in Crosslinked Polyethylene Liners
}

\author{
Kamal Bali MBBS, MS, DNB, Richard W. McCalden MD, MPhil, FRCSC, \\ Douglas D. R. Naudie MD, FRCSC, Steven J. MacDonald MD, FRCSC, \\ Matthew G. Teeter PhD
}

Published online: 23 July 2015

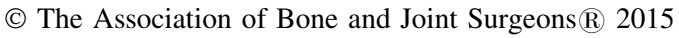

\begin{abstract}
Background Although it is understood that backside damage occurs in polyethylene acetabular liners, the effect of highly crosslinked polyethylene, which has completely replaced conventional polyethylene, has yet to be examined. Questions/purposes The purpose of this study was to answer the following questions: (1) With conventional polyethylene (CPE), did the acetabular design make a difference in backside wear? (2) Is there a difference in backside damage between CPE and crosslinked
\end{abstract}

The institution of one or more of the authors (RWM, DDRN, SJM, MGT) has received funding from Smith \& Nephew (Memphis, TN, USA), DePuy (Warsaw, IN, USA), and Stryker (Kalamazoo, MI, USA).

All ICMJE Conflict of Interest Forms for authors and Clinical Orthopaedics and Related Research ${ }^{\mathbb{R}}$ editors and board members are on file with the publication and can be viewed on request.

Clinical Orthopaedics and Related Research ${ }^{\mathbb{R}}$ neither advocates nor endorses the use of any treatment, drug, or device. Readers are encouraged to always seek additional information, including FDAapproval status, of any drug or device prior to clinical use. Each author certifies that his or her institution approved the human protocol for this investigation, that all investigations were conducted in conformity with ethical principles of research, and that informed consent for participation in the study was obtained.

This work was performed at Schulich School of Medicine \& Dentistry, Western University, London, Ontario, Canada.

K. Bali, R. W. McCalden, D. D. R. Naudie, S. J. MacDonald, M. G. Teeter $(\bowtie)$

Division of Orthopaedic Surgery, Department of Surgery, Schulich School of Medicine \& Dentistry, Western University, 339 Windermere Road, London, Ontario N6A 5A5, Canada

e-mail: matthew.teeter@1hsc.on.ca

M. G. Teeter

Department of Medical Biophysics, Schulich School of

Medicine \& Dentistry, Western University, London, Ontario,

Canada polyethylene (XLPE) liners? (3) With XLPE, is the difference in backside wear between designs still present? (4) Is there any difference in backside damage in various zones on backside of individual liners?

Methods This single-institution retrieval analysis involved visual damage scoring on the backside of 233 polyethylene liners implanted between 2002 and 2011. The liners were retrieved from either polished/dovetail cups (PD) or roughened/wire cups (RW) made by two different manufacturers. The inserts were divided into four groups: PD-CPE ( $\mathrm{n}=105)$, PD-XLPE $(\mathrm{n}=16)$, RW-CPE ( $\mathrm{n}=99)$, and RW-XLPE $(n=13)$. Aseptic loosening and polyethylene wear were the predominant reasons for revision of CPE liners, whereas instability and infection were the common reasons for revision of XLPE liners. The time in situ (TIS) was shorter for the XLPE liners as compared with the CPE liners (PD-CPE: 8.5 years [SD 4.4]; RDCPE: 9.5 [SD 4.8]; PD-CPE: 3.8 [SD 3.7]; RD-XLPE: 4.0 [SD 4.3]). The backside of each liner was divided into five zones and graded initially from a scale of 0 to 3 for seven different damage modes by one observer. There was substantial interobserver (kappa 0.769) and intraobserver (0.736) reliability on repeat scoring. To compare the effects of crosslinking, a subset of the conventional polyethylene liners was matched to the crosslinked liners based on TIS,

M. G. Teeter

The Surgical Innovation Program, Lawson Health Research Institute, London, Ontario, Canada 
resulting in 16 per group for the two PD types and 13 per group for the two RW types.

Results Total damage scores in the RW-CPE $(19 \pm 7)$ group were greater $(\mathrm{p}<0.001)$ than the PD-CPE group $(8 \pm$ 4). Damage was reduced with XLPE $(p=0.02)$ only for the RW-XLPE $(9 \pm 9)$ versus RW-CPE-type sockets $(4 \pm 4)$. There was no difference $(p=0.16)$ between the RW-XLPE group and the PD-XLPE group. Damage scores in the peripheral zone of the locking mechanisms were higher for RW-CPE $(4 \pm 3)$ compared with PD-CPE $(1.4 \pm 1.0, \mathrm{p}<$ $0.001)$ and RW-XLPE $(1.3 \pm 1.3, \mathrm{p}=0.02)$. Damage was greater $(\mathrm{p}<0.001)$ within the superior zones $(7 \pm 4)$ compared with the inferior zones $(3.0 \pm 2.8)$ of all liners.

Conclusions The current study shows greater backside damage for CPE in the roughened, wire lock cups. XLPE was shown to be more resistant to backside damage for both socket designs.

Clinical Relevance Although the polished/dovetail cups seem to cause less backside damage in the CPE liners than roughened/wire cups, the use of XLPE liners has been shown to protect the liner from backside damage in either cup design. If an acetabular shell has a functional locking mechanism, surgeons should not worry about cup design when undertaking isolated liner revision using XLPE liners.

\section{Introduction}

Periprosthetic osteolysis, as a result of polyethylene wear, has been an important cause of long-term failure in THA using conventional polyethylene (CPE) and wear and lysis remain open questions in the era of crosslinked polyethylene (XLPE) [3, 14, 20, 21, 24, 42, 47]. Apart from the articular side, the interface between the liner and metal socket is also a potential source of polyethylene debris in modern modular acetabular implants [1, 12, 23, 25, 28, 29, 36, 43, 45]. Although articular-sided wear of polyethylene has been well documented and quantified [3, 14, 20, 21, 24, 42, 47], the role of backside wear in modern modular prostheses continues to be controversial because even less is known about backside wear with this newer material $[1,12,25]$.

In vitro studies $[4,8,15,26,28-30,36,44]$ have evaluated different design aspects affecting the amount of backside wear/damage. These have included: the shell-liner conformity, the locking mechanism, the surface finish of the inner surface of the metal socket, the use of screws, the number of screw holes, the thickness of the liner and liner type, and the role of XLPE versus CPE $[4,8,15,26,28-30$, $36,44]$. However, a cause-effect relationship has not been clearly established by these in vitro studies. A few retrieval studies [1, 12, 23, 25, 43, 45] have also been performed involving direct visual/volumetric assessment of backside wear. However, gaps persist in our knowledge, and there are limited data regarding the in vivo backside wear characteristics of polyethylene liners (especially that of XLPE) and we have a limited understanding of what the important factors are that contribute to backside wear.

Various design features of modern acetabular implants can affect backside damage of polyethylene. Polished acetabular components have been developed by some manufacturers in an attempt to decrease backside polyethylene wear. Although some in vitro studies have shown a decreased amount of backside wear with polishing of the acetabular surface $[8,30]$, others have shown no difference $[26,36]$. To our knowledge, no retrieval study has compared backside damage in acetabular shells with roughened and polished inner surfaces. Another potential design feature affecting backside damage is the locking mechanism of modular acetabular sockets. A poor locking mechanism (associated with micromotion of acetabular liners) has been implicated as a causative factor for increased backside wear contributing to osteolysis $[8,15,44]$. Although there has been one retrieval study [43] that showed higher backside wear with poorly locked acetabular liners, none of the studies have actually compared the in vivo backside damage for flexible and rigid locking mechanisms in modern modular acetabular implants. Finally, the advent of XLPE has clearly changed the articular-sided wear pattern in THA [5$7,13,27,31,39]$. XLPE has been increasingly shown to be more resistant to articular-sided wear in both in vitro and in vivo studies [5-7, 13, 27, 31, 39]. In addition, XLPE may have the potential to offset the effect of some of the design features of modular acetabular implants associated with higher backside wear.

The primary purpose of this retrieval study was to determine if there were differences in visual damage scores on the backside of modular polyethylene liners for two commonly implanted acetabular sockets: Duraloc (DePuy, Warsaw, IN, USA), which has a roughened inner surface and flexible metal locking wire (Fig. 1A), and Reflection (Smith \& Nephew, Memphis, TN, USA), which has a polished inner surface and tapered dovetail locking tabs (Fig. 1B). The questions posed for this study were: (1) With CPE, did the acetabular design make a difference in backside wear? (2) Is there a difference in backside damage between CPE and XLPE liners? (3) With XLPE, is the difference in backside wear between designs still present? (4) Is there any difference in backside damage in various zones on backside of individual liners?

\section{Materials and Methods}

The current study was a retrieval analysis that involved visual damage scoring of 233 modular polyethylene inserts for Reflection (polished surface/dovetail locking tabs [PD]) 
Fig. 1A-D This figure shows photographs of the two cups assessed in this study: (A) Duraloc cup has a rough inner surface; (B) Reflection cup has a polished inner surface; $(\mathbf{C})$ closeup image of the Duraloc cup shows its rigid dovetail locking mechanism; (D) closeup image of the Reflection socket shows its flexible wire locking mechanism.

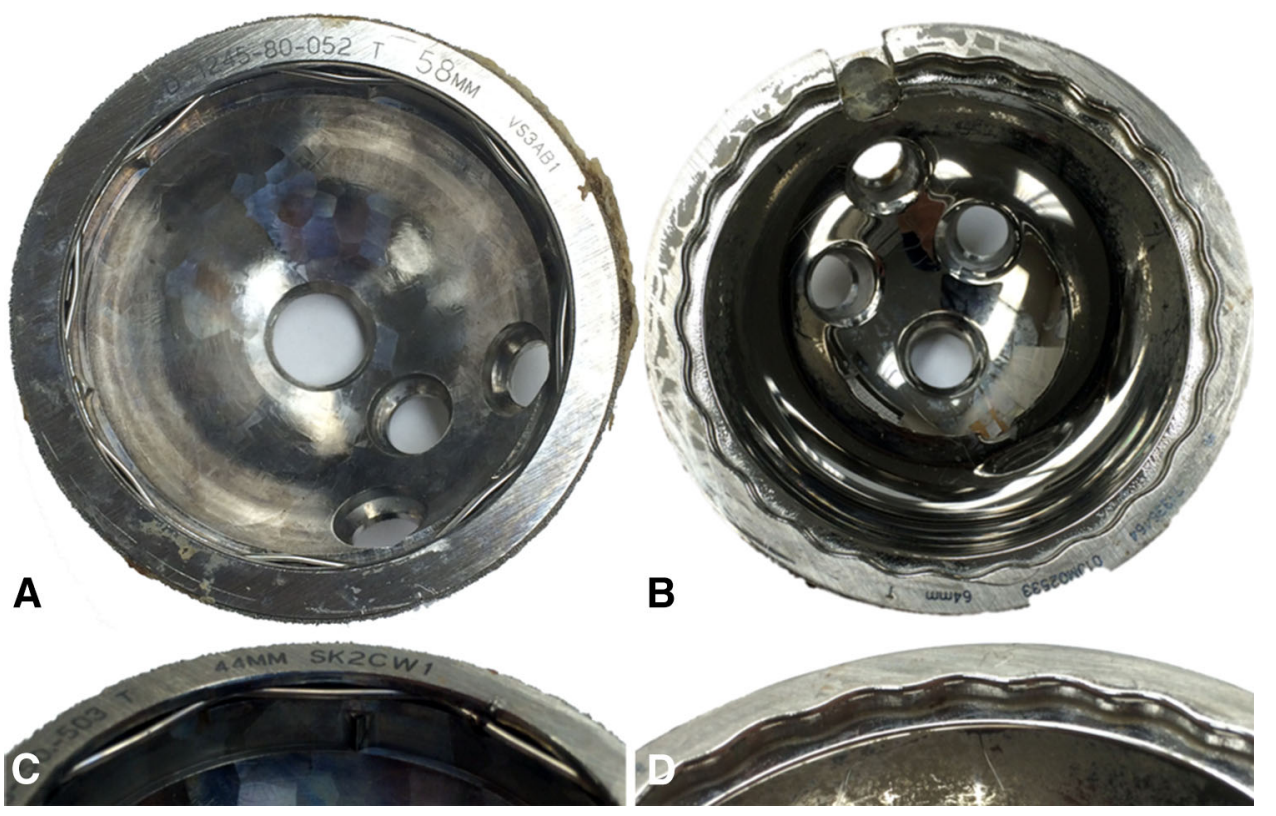

and Duraloc (rough surface/wire lock [RW]) acetabular sockets (Fig. 1A-D). Structurally, the Duraloc shell has a roughened (matte) inner surface as compared with the Reflection shell, which is highly polished. The Duraloc and Reflection shells also differ in their locking mechanism of polyethylene liner. The Duraloc shell has a flexible metal locking wire that prevents push-out of the liner. However, there is no mechanism in the Duraloc shell to prevent rotational slippage of the liner inside the metal shell and there have been a few reports of failure of the locking ring mechanism of the Duraloc shells leading to polyethylene wear [33]. The Reflection shell, on the other hand, has tapered dovetail peripheral locking tabs and achieves rigid peripheral locking of the liner inside the shell.

These inserts have been collected during revision THAs performed at our institution between 2002 and 2013 and stored in our large ongoing institutional review boardapproved implant retrieval laboratory. Demographic data were obtained from patient records for each retrieved liner and included age at the time of revision, sex, side, time in situ for the liners, body mass index (BMI), and reason for revision.

The inserts were divided into two broad types: PD $(\mathrm{n}=121)$ and RW $(\mathrm{n}=112)$; and subdivided into four groups: PD-CPE $(\mathrm{n}=105)$, PD-XLPE $(\mathrm{n}=16)$, RW-CPE ( $n=99)$, and RW-XLPE $(n=13)$ depending on the type of polyethylene material used. Thus, the PD-CPE group included conventional polyethylene inserts from Reflection sockets; the PD-XLPE group included highly crosslinked polyethylene inserts from Reflection sockets; the RW-CPE included conventional Enduron polyethylene inserts from Duraloc sockets; and the RW-XLPE included highly crosslinked Marathon polyethylene inserts from Duraloc sockets.
Table 1. Demographic profile of liners

\begin{tabular}{lllll}
\hline Liner & Number & $\begin{array}{l}\text { Age } \\
(\text { years } \pm \mathrm{SD})\end{array}$ & $\begin{array}{l}\text { BMI } \\
\left(\mathrm{kg} / \mathrm{m}^{2} \pm \mathrm{SD}\right)\end{array}$ & $\begin{array}{l}\text { Time in vivo } \\
(\text { years } \pm \mathrm{SD})\end{array}$ \\
\hline PD-CPE & 105 & $58 \pm 15$ & $30 \pm 6$ & $8.5 \pm 4$ \\
PD-XLPE & 16 & $64 \pm 12$ & $37 \pm 4$ & $3.8 \pm 4$ \\
RW-CPE & 99 & $61 \pm 14$ & $29 \pm 6$ & $9.5 \pm 5$ \\
RW-XLPE & 13 & $60 \pm 16$ & $31 \pm 10$ & $4.0 \pm 4$ \\
p value & & $0.22^{*}$ & $0.09^{\dagger}$ & $<0.0001^{\dagger, *}$ \\
\hline
\end{tabular}

* One-way analysis of variance test; ${ }^{\dagger}$ Kruskal-Wallis test; ${ }^{*}$ statistically significant; $\mathrm{BMI}=$ body mass index; $\mathrm{PD}=$ polished/dovetail cups; $\mathrm{CPE}=$ conventional polyethylene; $\mathrm{XLPE}=$ highly crosslinked polyethylene; RW = roughened/wire cups.

The demographics (Table 1) and reasons for revision (Table 2) were similar among the four groups with the exception of time in situ. The XLPE groups were implanted for a shorter duration than the CPE groups. There was no difference in time in situ between PD-CPE and RW-CPE or between PD-XLPE and RW-XLPE. Therefore, to compare the effects of surface roughness and locking mechanisms, the implants were compared separately within the CPE and XLPE groups. To compare the effects of crosslinking, a subset of the conventional polyethylene liners was matched to the crosslinked liners based on time in situ, resulting in 16 per group for the two PD types and 13 per group for the two RW types.

The backside of each insert was divided into five zones (Fig. 2): anterosuperior (AS), anteroinferior (AI), posteroinferior (PI), posterosuperior (PS), and peripheral (PR). The 12 o'clock position was approximately identified for this primarily based on markings by the retrieving surgeon. This was secondarily confirmed by site of extraction marks in the 
Table 2. Reasons for revision in various subgroups

\begin{tabular}{lcccrrr}
\hline Group & Infection & Polyethylene wear & Aseptic loosening & Instability & Periprosthetic fracture & Others* \\
\hline RW-CPE & 6 & 35 & 32 & 6 & 8 & 12 \\
PD-CPE & 12 & 35 & 20 & 18 & 13 & 79 \\
RW-XLPE & 4 & 0 & 1 & 5 & 3 & 105 \\
PD-XLPE & 10 & 0 & 1 & 32 & 1 & 13 \\
Total & 31 & 71 & 54 & 24 & 16 \\
\hline
\end{tabular}

* Unknown pain, impingement, thigh pain, psoas bursitis (acetabular retroversion), etc; $\mathrm{RW}=$ roughened/wire cups; $\mathrm{CPE}=\mathrm{conventional}$ polyethylene; $\mathrm{PD}=$ polished/dovetail cups; $\mathrm{XLPE}=$ highly crosslinked polyethylene .

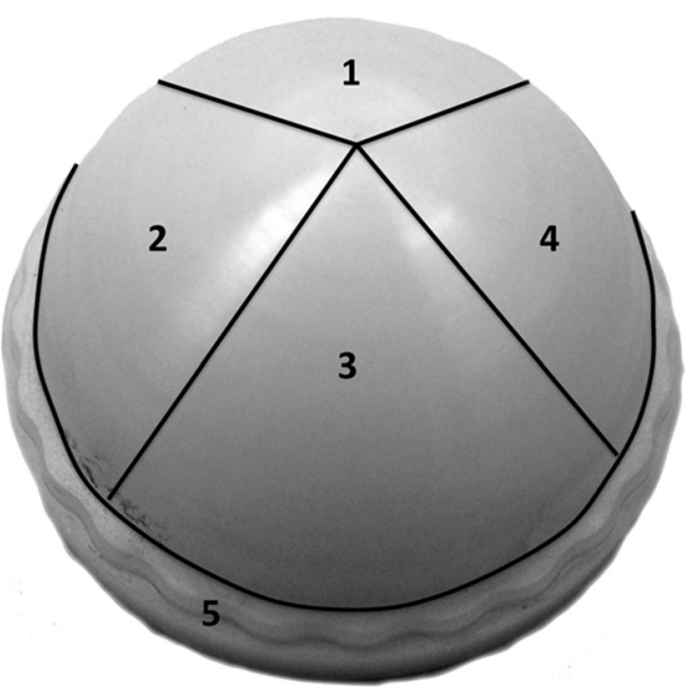

Fig. 2 Grid used for damage scoring has been shown in this image: $1=$ anterosuperior; $2=$ anteroinferior; $3=$ posteroinferior; $4=$ posterosuperior; and $5=$ peripheral.

insert, articular side wear pattern, and position of the lip, if present. After identification of the 12 o'clock position, the backside of the liners was divided into four equal quadrants and numbered clockwise (left) or counterclockwise (right). The PR zone was the site of the locking mechanism.

Each zone was subjectively graded from a scale of 0 to 3 for seven different damage modes (burnishing, abrasion, cold flow, scratching, pitting, delamination, and embedded debris). The damage score was 0 for no damage, 1 for $<$ $10 \%$ area affected (Fig. 3A), 2 for $10 \%$ to $50 \%$ area affected (Fig. 3B), and 3 for $>50 \%$ of area affected (Fig. 3C). The scoring system was based on previously established and validated protocols for damage scoring in retrieved polyethylene specimens $[11,22,32]$. The maximum possible damage score by this method was 105 . Initially a single observer (KB) graded all the 233 polyethylene inserts based on the scoring system. To ensure the validity of the damage scoring results, rescoring was performed for Zone 1 in a sample of 46 polyethylene liners taken evenly from the four groups (12 each from PD-CPE and RW-CPE and 11 each from PD-XLPE and RW-
XLPE). This sample size was based on established guidelines for achieving adequate power in reliability studies $[37,38]$. Scoring by a second observer (MGT) was done to confirm the interobserver agreement and by the first observer again to confirm the intraobserver reliability. Both observers were blinded to previous results at the time of rescoring. For interobserver reliability, the weighted kappa score was 0.769 , indicating substantial agreement. For intraobserver reliability, the weighted kappa score was 0.736 , also indicating substantial agreement in the reproducibility of results for the primary observer. Because the weighted kappa scores showed high interobserver and intraobserver reliability for the 46 polyethylene liners, no further rescoring was performed.

The D'Agostino and Pearson omnibus normality test was used to assess the distribution of the data, and the appropriate parametric or nonparametric tests were applied. Demographics between implant groups were assessed using a oneway analysis of variance (age) or Kruskal-Wallis test (BMI and implantation time). Unpaired comparisons of damage were performed using an unpaired t-test or Mann-Whitney test. Paired comparisons of damage were performed using a paired t-test or Wilcoxon matched-pairs signed-rank test. Correlation between damage scores and age, BMI, and time in vivo was performed using Spearman correlation and linear regression. Because the CPE groups had a longer implantation time (described later in the Results section), the XLPE groups were matched in a pairwise fashion to the CPE groups based on implantation time and age. A p value $<0.05$ was taken as statistically significant.

\section{Results}

With CPE, there was more backside damage with the rough surface/wire lock socket design than with the polished surface/dovetail socket design. Total damage scores (Table 3) in the RW-CPE $(19 \pm 7)$ group were greater $(\mathrm{p}<0.001)$ than the PD-CPE group $(8 \pm 4)$. The two most common damage modes were abrasion and burnishing, with scratching much more prevalent in the RW-CPE group. 


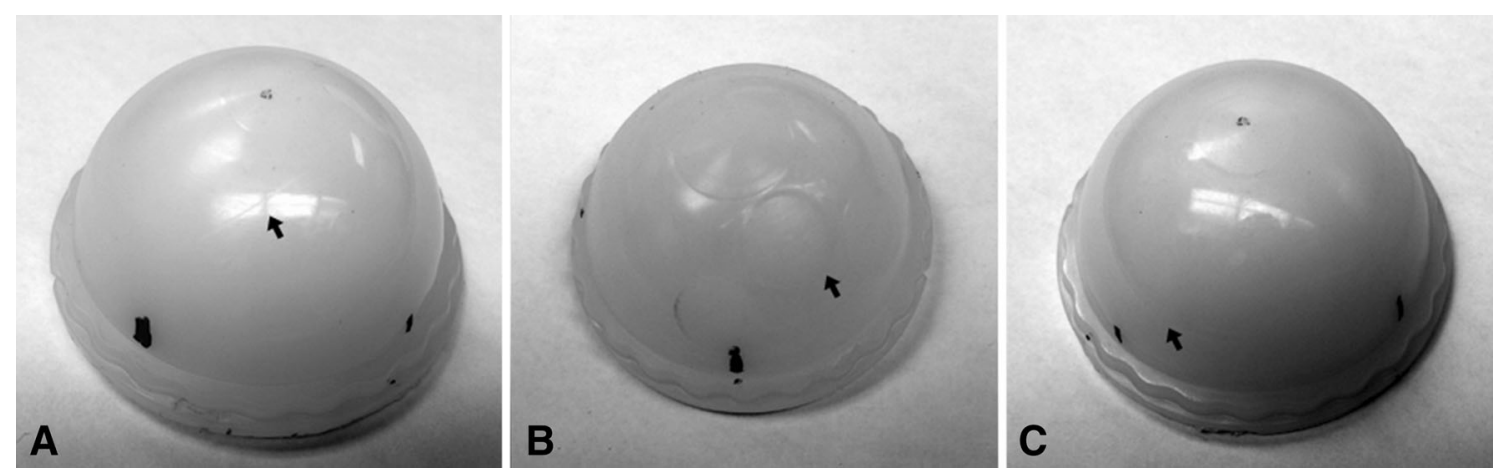

Fig. 3A-C This figure shows various grades and types of backside damage (arrows) in some of the retrieved liners: (A) shows Grade $1(<10 \%$ area) scratching; (B) shows Grade 2 (10\%-50\% area) cold flow; (C) shows Grade 3 (> 50\% area) burnishing.

Table 3. Total damage scores by group

\begin{tabular}{lll}
\hline Group & $\begin{array}{l}\text { Damage score } \\
(\text { mean } \pm \text { SD) }\end{array}$ & p value \\
\hline RW-CPE & $19 \pm 7$ & $<0.001$ \\
PD-CPE & $8 \pm 4$ & \\
RW-XLPE & $9 \pm 9$ & 0.16 \\
PD-XLPE & $4 \pm 4$ & \\
\hline
\end{tabular}

$\mathrm{RW}=$ roughened/wire cups; $\mathrm{CPE}=$ conventional polyethylene; $\mathrm{PD}=$ polished/dovetail cups; XLPE = highly crosslinked polyethylene.

Crosslinking reduced backside damage for the rough surface/wire lock socket design but not the polished surface/dovetail socket design. The total damage was reduced $(\mathrm{p}=0.02)$ with crosslinked polyethylene for the RW-XLPE $(9 \pm 9)$ versus RW-CPE-type sockets $(4 \pm 4)$. However, there was no difference between CPE and XLPE liners in the PD-type sockets $(\mathrm{p}=0.26)$. The three most common damage modes were abrasion, scratching, and pitting. The PD-XLPE group had more embedded debris and pitting than the RW-XLPE group.

When crosslinked polyethylene was used, there was no difference $(p=0.16)$ between the rough surface/wire lock socket design and the polished surface/dovetail socket. Age $(\mathrm{r}=-0.09, \mathrm{p}=0.16)$ and BMI $(\mathrm{r}=-0.02, \mathrm{p}=0.78)$ did not correlate with total damage scores for all the inserts (Fig. 4). However, a longer time in vivo was associated with higher total damage scores $(r=0.43, p<0.001)$. After matching the RW-XLPE and PD-XLPE group demographics, the total damage score in the matched RW-CPE group ( $\mathrm{n}=13$ ) was $15 \pm 7$ and $6 \pm 5$ in the matched PDCPE group $(\mathrm{n}=16)$.

The damage scores in the peripheral zone, which may reflect the effect of differences between locking mechanisms of the two socket designs, were higher for RW-CPEtype sockets as compared with the PD-CPE type ( $<<$ $0.001)$ and the RW-XLPE type $(\mathrm{p}=0.02)$. The mean damage scores in the PR zones were $4 \pm 3$ for RW-CPE,
$1.3 \pm 1.3$ for RW-XLPE, $1.4 \pm 1.0$ for PD-CPE, and $0.9 \pm$ 1.1 for PD-XLPE. Within the other zones (Table 4), damage was greater $(\mathrm{p}<0.001)$ within the superior zones $(\mathrm{AS}+\mathrm{PS}, 7 \pm 4)$ compared with the inferior zones (AI + PI, $3.0 \pm 2.8$ ). There was no evidence of rim fractures or cracking in any of the polyethylene inserts.

\section{Discussion}

Backside wear in polyethylene liners continues to be controversial and there is a lacuna in the literature addressing the effect of cup design and polyethylene material (CPE or XLPE) on backside wear [4, 8, 15, 26, 28-30, 36, 44]. The Reflection and Duraloc sockets have been among the commonly implanted acetabular implants over the last two decades $[9,10,18,19,34,40,41]$. As such, surgeons performing revision THA will continue to deal with these sockets, especially in scenarios with the possibility of isolated liner revision where a well-fixed socket might be retained. We therefore asked the following: (1) With CPE, did the acetabular design make a difference in backside wear? (2) Is there a difference in backside damage between CPE and XLPE liners? (3) With XLPE, is the difference in backside wear between designs still present? (4) Is there any difference in backside damage in various zones on the backside of individual liners?

There are a few limitations of the current study. We did not perform correlations of our findings with articular wear in the current study. In addition, the cause of revision (especially infection and instability) may play a role in the amount of backside wear and this was not analyzed in the current study. Furthermore, visual backside damage (as measured in the current study) may not completely correspond with true volumetric wear. However, damage scoring is a valid and common method in retrieval studies $[11,22,32]$ and we found substantial inter- and intraobserver reliability of this method. The two socket designs 

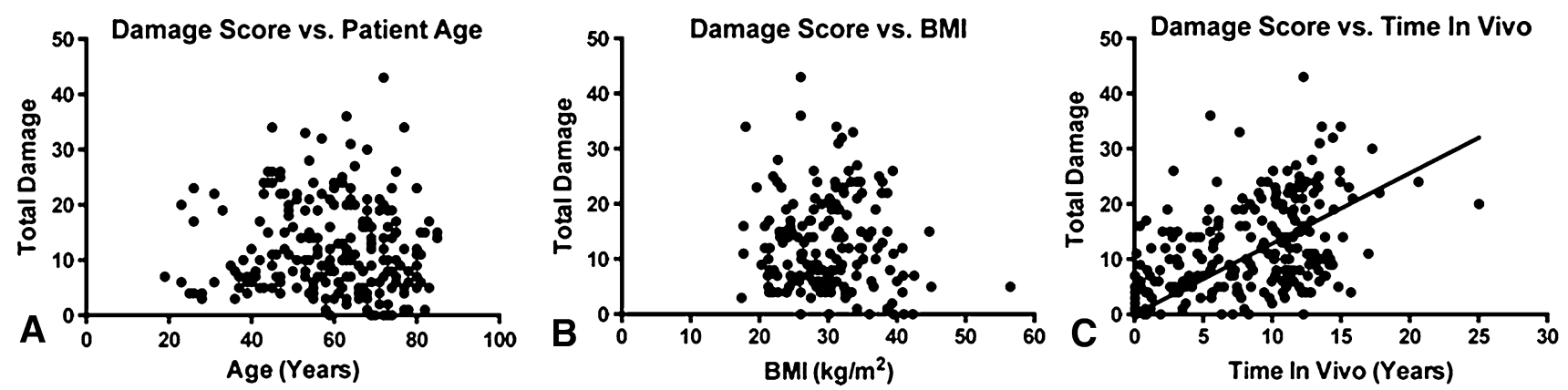

Fig. 4A-C This figure shows the correlation between damage scores and demographics with respect to (A) patient age; (B) BMI; and (C) time in situ. Linear regression has been set to intersect at 0,0 resulting in a slope of $y=1.3 x+0$.

Table 4. Total damage across all implants by zone

\begin{tabular}{ll}
\hline Zone & Damage score $($ mean $\pm \mathrm{SD})$ \\
\hline Anterosuperior & $4 \pm 2$ \\
Anteroinferior & $2 \pm 2$ \\
Posteroinferior & $1 \pm 2$ \\
Posterosuperior & $3 \pm 2$ \\
\hline
\end{tabular}

examined in this study were distinctly different with respect to both inner socket surface finish and locking mechanism; this makes it difficult to know the relative effect of each of these variables. Also, the alteration in wear properties can change the biological response to wear debris. Reactivity of the wear particles may depend on particle size and we did not study this. In addition, other factors that can potentially influence backside polyethylene wear in modular acetabular liners were not assessed, including differences in manufacturing and sterilization techniques, shell-liner conformity, the use of screws, the number of screw holes, the thickness and size of the liner used, evidence of neck impingement, radiographic parameters (ie, acetabular inclination/version), and clinical parameters (such as activity level of patient). Inclusion of all these factors would be challenging to evaluate in a study of this size, although we believe the large numbers (233 inserts) in the current study, in which only two acetabular designs were examined, were sufficient to support our conclusions with respect to backside polyethylene wear. As more crosslinked liners are revised over time, this will enable researchers in retrieval centers to examine such liners in greater numbers than the present study ( $\mathrm{n}=13$ and 16 in the Duraloc and Reflection groups, respectively) and to examine additional factors.

The current study found lesser backside damage for CPE in Reflection sockets with polished inner surfaces and a more robust locking mechanism. Previously published studies have not fully established the effect of polishing of the inside surface of modular sockets. In their respective in vitro studies involving long-term simultaneous sinusoidal and static loading, Lieberman et al. [30] and Chen et al. [8] showed less backside polyethylene wear in modular sockets with polished inside surfaces. However, contrary to these findings, the in vitro studies by Shepard et al. [36] and Kurtz et al. [26] did not show any relation between backside wear and polishing of the inner surface of modular sockets. None of the acetabular liners had severe backside damage. The maximum possible backside damage score by the system used in the current study was 105; however, the mean damage scores in the study ranged from only from 4 for PD-XLPE to 19 for RW-CPE. This reflects minimal to very low backside damage, which is comparable to the retrieval studies by Akbari et al. [1] and Krieg et al. [25]. However, the backside of the liner continues to be a source of particulate debris in THA and whether this backside wear is important enough to cause a strong osteolytic response in modern modular sockets remains to be answered.

We also found reduced backside damage in XLPE liners in comparison to the CPE liners. Although XLPE has been increasingly shown to be more resistant to articular-sided wear than the CPE [5-7, 13, 27, 31, 39], there have been no studies comparing backside wear in combination with surface treatment and locking mechanisms. We found similar backside damage for XLPE liners implanted in Duraloc sockets as compared with XLPE and CPE liners in Reflection sockets. Only the CPE liners in Duraloc sockets had higher backside damage scores. This finding suggests that XLPE seems to be more resistant to backside damage and tends to offset the deleterious effects of a roughened socket with a flexible locking mechanism. Although not proven by the current study, there may be a beneficial effect of XLPE on wear and potentially on osteolysis, which is reflected in the causes for revision of the retrieved implants in our study. Although polyethylene wear and aseptic loosening were important reasons for failure of CPE inserts, these were not seen with the XLPE inserts 
Table 5. Summary of various retrieval studies on backside wear in acetabular liners

\begin{tabular}{|c|c|c|c|c|c|}
\hline Authors & Year & Numbers & Shell type & Mean TIV & Results \\
\hline Huk et al. [23] & 1994 & $19 \mathrm{CPE}$ & $\begin{array}{l}4{\mathrm{HG}-\mathrm{I}^{\S}} 10{\mathrm{HG}-\mathrm{II}^{\S}} \\
2 \mathrm{ATH}^{+\dagger} \\
1 \text { each of Optifix, }{ }^{\dagger \dagger} \\
\text { Mallory head, }^{\dagger} \\
\text { and } \mathrm{APR}^{\S \S}\end{array}$ & 2 years & $\begin{array}{l}\text { Back surface of liner source of generation of } \\
\text { particulate debris }\end{array}$ \\
\hline $\begin{array}{l}\text { Yamaguchi } \\
\text { et al. [46] }\end{array}$ & 1999 & $90 \mathrm{CPE}$ & Osteonics & 3 years & $\begin{array}{l}\text { Backside wear may not be the result of micromotion } \\
\text { at interface but the viscoelastic nature of } \\
\text { polyethylene; acetabular osteolysis does not } \\
\text { correlate with backside wear }\end{array}$ \\
\hline $\begin{array}{l}\text { Della Valle } \\
\text { et al. [12] }\end{array}$ & 2005 & $36 \mathrm{CPE}$ & $\begin{array}{l}9 \text { each of Implex, } \\
\text { HG-I,III HG-IIIIII } \\
\text { and Trilogy }\end{array}$ & 2 years & $\begin{array}{l}\text { Significant reduction in the backside wear of modern } \\
\text { modular (Trilogy) and nonmodular (Implex) } \\
\text { acetabular components when compared with first- } \\
\text { generation modular designs (Harris-Galante } \\
\text { Types I and II) }\end{array}$ \\
\hline $\begin{array}{r}\text { Wasielewski } \\
\text { et al. [43] }\end{array}$ & 2005 & $55 \mathrm{CPE}$ & $\begin{array}{l}25{\mathrm{HG}-\mathrm{I}^{\S}}^{\S}{\mathrm{HG}-\mathrm{II}^{\S}}^{\S} \\
9 \mathrm{PCA}^{\|} \\
5 \text { Omnifit }^{\bullet} \\
5 \text { Duraloc }^{* *} \\
2 \text { Optifix }^{\dagger \dagger}\end{array}$ & 3 years & $\begin{array}{l}\text { Severe backside damage can occur with locking } \\
\text { mechanism failure; severe backside wear } \\
\text { correlates more strongly with osteolysis than does } \\
\text { articular-sided wear with osteolysis }\end{array}$ \\
\hline Krieg et al. [25] & 2009 & $35 \mathrm{CPE}$ & SL cup & 5 years & $\begin{array}{l}\text { Rate of backside volumetric change (predominantly } \\
\text { creep) only } 2.8 \% \text { of the rate of volumetric } \\
\text { articular wear }\end{array}$ \\
\hline Akbari et al. [2] & 2010 & $53 \mathrm{CPE}$ & $\begin{array}{l}16 \text { Impact }^{\dagger} \\
6 \text { Ringloc, } \\
31 \text { Microseal* }^{*}\end{array}$ & $\begin{array}{l}13 \text { years }(\text { Impact), } \\
10 \text { years (Ringloc), } \\
9 \text { years (Microseal) }\end{array}$ & $\begin{array}{l}\text { Backside damage higher for Impact and Ringloc } \\
\text { liners as compared with Microseal liners }\end{array}$ \\
\hline Akbari et al. [1] & 2011 & $56 \mathrm{CPE}$ & Microseal* & 6 years & $\begin{array}{l}\text { Half of liners exhibited minimal damage, half } \\
\text { exhibited no damage, and none exhibited severe } \\
\text { damage; backside damage correlated only to liner } \\
\text { age in vivo }\end{array}$ \\
\hline Pang et al. [32] & 2015 & $\begin{array}{l}13 \text { CPE } \\
13 \text { XLPE }\end{array}$ & Reflection $^{\S}$ & 5 years & $\begin{array}{l}\text { No difference in backside damage between groups; } \\
\text { the wear rate was three times greater in the CPE } \\
\text { group, significantly higher than the XLPE group }\end{array}$ \\
\hline Current study & - & $\begin{array}{l}204 \mathrm{CPE} \\
29 \mathrm{XLPE}\end{array}$ & $\begin{array}{l}121 \text { Reflection }^{\S} \\
112 \text { Duraloc }^{* *}\end{array}$ & $\begin{array}{l}9 \text { years Reflection CPE; } \\
4 \text { years Reflection XLPE; } \\
10 \text { years Duraloc CPE; } \\
4 \text { years Duraloc XLPE }\end{array}$ & $\begin{array}{l}\text { Higher backside damage for CPE in Duraloc-type } \\
\text { roughened cups with flexible wire locking } \\
\text { mechanism; Reflection-type cups with a polished } \\
\text { inner surface and a rigid locking mechanism more } \\
\text { protective against damage; XLPE more resistant } \\
\text { to backside damage for both socket designs }\end{array}$ \\
\hline
\end{tabular}

* Signal Medical Corp, St Louis, MO, USA; ${ }^{\dagger}$ Biomet, Warsaw, IN, USA; ${ }^{\star}$ ME Müller, Zimmer GmbH, Winterthur, Switzerland; ${ }^{\S}$ Zimmer, Warsaw, IN, USA; "Howmedica, Rutherford, NJ, USA; ${ }^{\top}$ Osteonics, Allendale, NJ, USA; **DePuy, Warsaw, IN, USA; ${ }^{\dagger}$ Richards, Memphis,

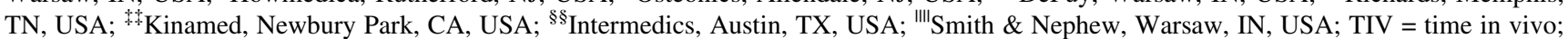
$\mathrm{CPE}=$ conventional polyethylene; $\mathrm{XLPE}=$ highly crosslinked polyethylene .

(Table 2). We found no evidence of an increased propensity for rim fracturing or cracking with the XLPE liners, which has been reported in some previous studies [16, 17, 35].

We also specifically evaluated the damage scores in the peripheral zone of the liner that contacts with the locking mechanism in the shell. Higher damage scores in the peripheral zones of Duraloc socket suggest higher in vivo micromotion of liner in this socket as compared with the
Reflection socket. As far as the locking mechanism is concerned, Fehring et al. [15] and Williams et al. [44] reported less micromotion for liners with Reflection shells as compared with the Duraloc shells during in vitro testing. Decreased micromotion has also been shown to be associated with less backside polyethylene debris generation in laboratory testing $[8,44]$. However, none of the studies have compared the in vivo backside damage for these two cups 
with differing locking mechanisms. The damage scores were also higher in the superior zones as compared with the inferior zones on the backside. This correlates with the direction of joint reaction forces in the hip and higher articular-sided polyethylene wear vector in vivo [46].

Considering the enormous number of modular cementless sockets that have been implanted worldwide, there are relatively few studies examining backside polyethylene wear. We have summarized these studies (Table 5). The relatively small number of retrieved liners reported on coupled with the lack of comparative groups within these studies limits their ability to draw solid conclusions. The current study, with much larger number of retrieved liners, shows higher backside damage in CPE liners, higher backside damage with rough/flexible wire-type sockets, and an apparent protective effect of XLPE on backside damage in any kind of acetabular socket. We also noted a correlation of backside damage scores with linear time in vivo for the inserts. The age of the patient, height, weight, or BMI had no correlation with damage scores. These results were in line with the previous retrieval study by Akbari et al. [1]. Most of the other retrieval studies have not commented on the correlation of wear with patient demographics.

In conclusion, the current study notes the influence of both design and materials on backside polyethylene damage in modern modular acetabular sockets. Although the backside wear is, in general, low for retrieved acetabular liners, CPE liners have higher associated backside damage. This may be particularly relevant for CPE liners implanted in Duraloc-like roughened cups with a flexible wire locking mechanism; and this is a combination that should be carefully watched for the sequelae of backside damage. A socket with a polished inner surface and a rigid locking mechanism appears be a better design with in the setting of CPE. The use of XLPE liners, however, has been shown in the current study to protect the liner from backside damage in either cup design. With a competent, intact locking mechanism, and use of crosslinked polyethylene, revision arthroplasty surgeons may not need to worry about cup design when undertaking isolated liner revision.

\section{References}

1. Akbari A, Roy ME, Whiteside LA, Katerberg BJ, Schnettgoecke DJ. Minimal backside surface changes observed in retrieved acetabular liners. J Arthroplasty. 2011;26:686-692.

2. Akbari A, Roy ME, Whiteside LA, Minteer SD. The influence of locking mechanism on screw-hole osteolysis and backside damage in long-term acetabular liners retrieved from revision total hip arthroplasty. Trans Soc Biomater. 2010;32:104.

3. Amstutz HC, Campbell P, Kossovsky N, Clarke IC. Mechanism and clinical significance of wear debris-induced osteolysis. Clin Orthop Relat Res. 1992;276:7-18.
4. Bartel DL, Burstein AH, Toda MD, Edwards DL. The effect of conformity and plastic thickness on contact stresses in metalbacked plastic implants. J Biomech Eng. 1985;107:193-199.

5. Bragdon CR, Doerner M, Martell J, Jarrett B, Palm H; Multicenter Study Group, Malchau H. The 2012 John Charnley Award: Clinical multicenter studies of the wear performance of highly crosslinked remelted polyethylene in THA. Clin Orthop Relat Res. 2013;471:393-402.

6. Burroughs BR, Muratoglu OK, Bragdon CR, Wannomae KK, Christensen S, Lozynsky AJ, Harris WH. In vitro comparison of frictional torque and torsional resistance of aged conventional gamma-in-nitrogen sterilized polyethylene versus aged highly crosslinked polyethylene articulating against head sizes larger than $32 \mathrm{~mm}$. Acta Orthop. 2006;77:710-718.

7. Callary SA, Field JR, Campbell DG. Low wear of a second-generation highly crosslinked polyethylene liner: a 5-year radiostereometric analysis study. Clin Orthop Relat Res. 2013;471:3596-3600.

8. Chen PC, Mead EH, Pinto JG, Colwell CW Jr. Polyethylene wear debris in modular acetabular prostheses. Clin Orthop Relat Res. 1995;317:44-56.

9. Civinini R, D'Arienzo M, Innocenti M 2nd. A ten-year follow-up of the Reflection cementless acetabular component. J Bone Joint Surg Br. 2008;90:570-573.

10. Clement ND, Mitchell M, Trayner ME, Porter DE, Lawson GM, Burnett R. Accelerated polyethylene wear and early failure of the uncemented Reflection acetabular component: a ten to fifteenyear follow-up study. Int Orthop. 2013;37:2337-2343.

11. Davidson JA, Schwartz G, Lynch G, Gir S. Wear, creep, and frictional heating of femoral implant articulating surfaces and the effect on long-term performance-Part II, friction, heating, and torque. J Biomed Mater Res. 1988;22(Suppl):69-91.

12. Della Valle AG, Rana A, Furman B, Sculco TP, Salvati EA. Backside wear is low in retrieved modern, modular, and nonmodular acetabular liners. Clin Orthop Relat Res. 2005;440:184-191.

13. Digas G, Kärrholm J, Thanner J, Malchau H, Herberts P. The Otto Aufranc Award. Highly cross-linked polyethylene in total hip arthroplasty: randomized evaluation of penetration rate in cemented and uncemented sockets using radiostereometric analysis. Clin Orthop Relat Res. 2004;429:6-16.

14. Dumbleton JH, Manley MT, Edidin AA. A literature review of the association between wear rate and osteolysis in total hip arthroplasty. J Arthroplasty. 2002;17:649-661.

15. Fehring TK, Smith SE, Braun ER, Mobley C, Wang PL, Griffin WL. Motion at the modular acetabular shell and liner interface. A comparative study. Clin Orthop Relat Res. 1999;367:306-314.

16. Furmanski J, Anderson M, Bal S, Greenwald AS, Halley D, Penenberg B, Ries M, Pruitt L. Clinical fracture of cross-linked UHMWPE acetabular liners. Biomaterials. 2009;30:5572-5582.

17. Furmanski J, Kraay MJ, Rimnac CM. Crack initiation in retrieved cross-linked highly cross-linked ultrahigh-molecular-weight polyethylene acetabular liners: an investigation of 9 cases. J Arthroplasty. 2011;26:796-801.

18. Grobler GP, Learmonth ID, Bernstein BP, Dower BJ. Ten-year results of a press-fit, porous-coated acetabular component. $J$ Bone Joint Surg Br. 2005;87:786-789.

19. Hallan G, Dybvik E, Furnes O, Havelin LI. Metal-backed acetabular components with conventional polyethylene: a review of 9113 primary components with a follow-up of 20 years. $J$ Bone Joint Surg Br. 2010;92:196-201.

20. Harris WH. Osteolysis and particle disease in hip replacement. A review. Acta Orthop Scand. 1994;65:113-123.

21. Harris WH. Wear and periprosthetic osteolysis: the problem. Clin Orthop Relat Res. 2001;393:66-70.

22. Hood RW, Wright TM, Burstein AH. Retrieval analysis of total knee prostheses: a method and its application to 48 total condylar prostheses. J Biomed Mater Res. 1983;17:829-842. 
23. Huk OL, Bansal M, Betts F, Rimnac CM, Lieberman JR, Huo $\mathrm{MH}$, Salvati EA. Polyethylene and metal debris generated by non-articulating surfaces of modular acetabular components. J Bone Joint Surg Br. 1994;76:568-574.

24. Kabo JM, Gebhard JS, Loren G, Amstutz HC. In vivo wear of polyethylene acetabular components. J Bone Joint Surg Br. 1993;75:254-258.

25. Krieg AH, Speth BM, Ochsner PE. Backside volumetric change in the polyethylene of uncemented acetabular components. J Bone Joint Surg Br. 2009;91:1037-1043.

26. Kurtz SM, Edidin AA, Bartel DL. The role of backside polishing, cup angle, and polyethylene thickness on the contact stresses in metalbacked acetabular components. J Biomech. 1997;30:639-642.

27. Kurtz SM, Gawel HA, Patel JD. History and systematic review of wear and osteolysis outcomes for first-generation highly crosslinked polyethylene. Clin Orthop Relat Res. 2011;469:2262-2277.

28. Kurtz SM, Ochoa JA, Hovey CB, White CV. Simulation of initial frontside and backside wear rates in a modular acetabular component with multiple screw holes. J Biomech. 1999;32:967-976.

29. Kurtz SM, Ochoa JA, White CV, Srivastav S, Cournoyer J. Backside nonconformity and locking restraints affect liner/shell load transfer mechanisms and relative motion in modular acetabular components for total hip replacement. J Biomech. 1998;31:431-437.

30. Lieberman JR, Kay RM, Hamlet WP, Park SH, Kabo JM. Wear of the polyethylene liner-metallic shell interface in modular acetabular components. An in vitro analysis. J Arthroplasty. 1996;11:602-608.

31. McCalden RW, MacDonald SJ, Rorabeck CH, Bourne RB, Chess DG, Charron KD. Wear rate of highly cross-linked polyethylene in total hip arthroplasty. A randomized controlled trial. $J$ Bone Joint Surg Am. 2009;91:773-782.

32. Pang HN, Naudie DD, McCalden RW, MacDonald SJ, Teeter MG. Highly crosslinked polyethylene improves wear but not surface damage in retrieved acetabular liners. Clin Orthop Relat Res. 2015;473:463-468.

33. Powers CC, Fricka KB, Austin MS, Engh CA Sr. Five Duraloc locking ring failures. $J$ Arthroplasty. 2010;25:1170.e15-18.

34. Powers CC, Ho H, Beykirch SE, Huynh C, Hopper RH Jr, Engh CA Jr, Engh CA. A comparison of a second- and a third-generation modular cup design: is new improved? J Arthroplasty. 2010;25:514-521.

35. Schroder DT, Kelly NH, Wright TM, Parks ML. Retrieved highly crosslinked UHMWPE acetabular liners have similar wear damage as conventional UHMWPE. Clin Orthop Relat Res. 2011;469:387-394.

36. Shepard MF, Lieberman JR, Kabo JM. Ultra-high-molecular weight polyethylene wear: an in vitro comparison of acetabular metal types and polished surfaces. J Arthroplasty. 1999;14:860866.

37. Shoukri MM, Asyali MH, Donner A. Sample size requirements for the design of reliability study: review and new results. Stat Methods Med Res. 2004;13:251.

38. Shoukri MM, Donner A. Efficiency considerations in the analysis of inter-observer agreement. Biostatistics. 2001;2:323-336.

39. Snir N, Kaye ID, Klifto CS, Hamula MJ, Wolfson TS, Schwarzkopf R, Jaffe FF. 10-year follow-up wear analysis of firstgeneration highly crosslinked polyethylene in primary total hip arthroplasty. J Arthroplasty. 2014;29:630-633.

40. Teo YS, Corten K, McCalden RW, Macdonald SJ, Bourne RB. The minimum 10-year results of a second-generation cementless acetabular shell with a polished inner surface. J Arthroplasty. 2012;27:1370-1375.

41. Thirion T, Georis P, Gillet P. Migration and wear of the Duraloc '1200 series' cup associated with Enduron UHWMPE using the EBRA method and the Imagika software. Hip Int. 2010;20:198203.

42. Urban RM, Hall DJ, Della Valle C, Wimmer MA, Jacobs JJ, Galante JO. Successful long-term fixation and progression of osteolysis associated with first-generation cementless acetabular components retrieved post mortem. J Bone Joint Surg Am. 2012;94:1877-1885.

43. Wasielewski RC, Jacobs JJ, Arthurs B, Rubash HE. The acetabular insert-metal backing interface: an additional source of polyethylene wear debris. J Arthroplasty. 2005;20:914-922.

44. Williams VG 2nd, Whiteside LA, White SE, McCarthy DS. Fixation of ultrahigh-molecular-weight polyethylene liners to metal-backed acetabular cups. J Arthroplasty. 1997;12:25-31.

45. Yamaguchi M, Bauer TW, Hashimoto Y. Deformation of the acetabular polyethylene liner and the backside gap. J Arthroplasty. 1999;14:464-469.

46. Yamaguchi M, Hashimoto Y, Akisue T, Bauer TW. Polyethylene wear vector in vivo: a three-dimensional analysis using retrieved acetabular components and radiographs. J Orthop Res. 1999;17:695702.

47. Young AM, Sychterz CJ, Hopper RH Jr, Engh CA. Effect of acetabular modularity on polyethylene wear and osteolysis in total hip arthroplasty. J Bone Joint Surg Am. 2002;84:58-63. 